\title{
Neisseria elongata
}

National Cancer Institute

\section{Source}

National Cancer Institute. Neisseria elongata. NCI Thesaurus. Code C123423.

A species of nonmotile, aerobic, catalase-negative, asaccharolytic, oxidase-positive, urea-negative, gram-negative coccobacillus bacterium in the family Neisseriaceae. It is found in the oral bacterial flora of the human pharynx and throat. In rare cases $\mathrm{N}$. elong ata is a causative agent of bacterial endocarditis. 